\title{
Implementasi Augmented Reality Pada Hardware Komputer Berbasis Android
}

\section{IMPLEMENTATION OF ANDROID BASED AUGMENTED REALITY FOR COMPUTER HARDWARE}

\author{
Muhammad Fahmi Rayda ${ }^{1}$, Edy Victor Haryanto ${ }^{2}$, Adil Seiawan ${ }^{3}$ \\ ${ }^{1}$ Jurusan Teknik Informatika Universitas Potensi Utama \\ ${ }^{2,3}$ Dosen Jurusan Teknik Informatika Universitas Potensi Utama \\ Universitas Potensi Utama, Jl.K.L. Yos Sudarso Km. 6,5 No 3A Tanjung Mulia Medan \\ Email : rayderxz@gmail.com,edyvictor@gmail.com
}

\begin{abstract}
Abstrak
Pada perkembangan teknologi yang semakin pesat, sehingga mendorong untuk mempermudah aktivitas manusia. Salah satu diantaranya adalah pendidikan yang membutuhkan teknologi dalam penerapan sistem pembelajaran sehingga menjadi efektif dan fleksibel. Augmented Reality merupakan penggabungan benda-benda nyata dan maya yang berada di lingkungan nyata dalam waktu yang nyata dan terintegrasi dengan baik dan jelas. Augmented Reality juga dapat memberikan kelebihan dalam interaksi antara manusia dengan komputer. Dengan adanya Teknologi Augmented Reality, dapat menjadi sebuah solusi dalam menerapkan proses belajar mengajar terutama pada pendidikan jurusan komputer, yang lebih interaktif menggunakan $3 D$ dibandingkan dengan versi sebelumnya yaitu media 2D. Dalam aplikasi ini objek 3D yang dihasilkan berdasarkan gambar asli sehingga pengguna seperti melihat benda aslinya. kelebihan pada aplikasi yang dihasilkan objek dapat diputar sehingga objek dapat dilihat secara jelas pada setiap sisinya. jadi diharapkan aplikasi yang dihasilkan juga dapat memberi banyak manfaat kepada pengguna untuk mengenal dan mengetahui bentuk hardware komputer secara jelas dan mudah dipahami.
\end{abstract}

Kata Kunci : Augmented Reality, Hardware Komputer,Android

\begin{abstract}
In the rapid development of technology, thus encouraging to facilitate human activity. One of them is education that requires technology in applying the learning system so that it becomes effective and flexible. Augmented Reality is an amalgamation of real and virtual objects that are in real environment in real time and well integrated and clear. Augmented Reality can also provide advantages in the interaction between humans and computers. With Augmented Reality Technology, it can be a solution in applying teaching and learning process especially in computer majors education, which is more interactive using $3 D$ compared to previous version that is $2 D$ media. In this app the 3D object is generated based on the original image so that the user is like seeing the original object. the advantages of the resulting application object can be rotated so that the object can be seen clearly on each side. so it is expected that the resulting application can also provide many benefits to the user to know and know the form of computer hardware clearly and easily understood.
\end{abstract}

Keywords : Augmented Reality, Hardware Computer,Android 


\section{PENDAHULUAN}

Dengan seiring berkembang pesatnya ilmu pengetahuan dan teknologi informasi pada era globalisasi dan serba modern akan kecanggihan teknologi yang dimiliki. Hal ini menjadikan teknologi sebagai kebutuhan dalam mempermudah aktivitas manusia sehari - hari, seperti aktivitas militer, pemerintah, perkantoran, hiburan dan lainnya. Salah satu diantaranya adalah pendidikan, dengan adanya penerapan teknologi yang canggih tentunya dapat membantu aktivitas dalam sistem belajar mengajar.

Adapun teknologi yang dimaksud adalah Augmented Reality (AR) yang merupakan gagasan atau ide baru dari teknologi yang berhubungan dalam bidang desain grafis dan berkaitan dengan multimedia. Secara garis besar, Augmented Reality merupakan penggabungan benda-benda nyata dan maya yang berada di lingkungan nyata dalam waktu yang nyata dan terintegrasi dengan baik dan jelas.

Sejarah tentang Augmented Reality dimulai dari tahun 1957-1962, ketika seorang penemu yang bernama Morton Heilig, seorang sinematografer, menciptakan dan mempatenkan sebuah simulator yang disebut Sensorama dengan visual, getaran dan bau. Pada tahun 1966, Ivan Sutherland menemukan head-mounted display yang dia claim adalah, jendela ke dunia virtual.

Dalam konteks ini, AR dapat diterapkan dalam dunia pendidikan, karena dapat memberikan informasi yang praktis, mudah dipahami dan dapat menggambarkan ilustrasi dari informasi yang diberikan. Hal ini, didorong karena penggunaan teknologi pada bidang pendidikan di Indonesia belum memadai yang disebabkan beberapa faktor, salah satu diantaranya adalah penggadaan fasilitas dalam proses belajar mengajar yang belum diterapkan dengan teknologi AR khususnya dalam hal mengenal perangkat-perangkat yang terdapat pada komputer, terutama perangkat keras (hardware) komputer. Hal tersebut ternyata masih banyak yang belum mengetahui hardware komputer secara lebih detail beserta fungsinya, yang disebabkan karena belum adanya alat peraga yang mendukung untuk memberikan ilustrasi yang dibutuhkan. Maka dari itu, penulis berkeinginan untuk menerapkan teknologi AR sehingga diharapkan dapat memberikan kemudahan dan relevansi untuk pendukung sistem belajar mengajar agar lebih baik secara kualitas maupun kuantitas kepada pengguna (user). Dengan tujuan untuk memberikan manfaat dan kemudahan terhadap pengguna dalam mengenal, mengetahui dan memahami.

\section{METODOLOGI PENELITIAN}

Augmented Reality adalah penggabungan benda-benda nyata dan maya di lingkungan nyata, berjalan secara interaktif dalam waktu nyata, dan terdapat integrasi antar benda dalam tiga dimensi, yaitu benda maya terintegrasi dalam dunia nyata. Penggabungan benda nyata dan maya dimungkinkan dengan teknologi tampilan yang sesuai, interaktivitas dimungkinkan melalui perangkat-perangkat input tertentu, dan integrasi yang baik memerlukan penjejakan yang efektif. [1]

Ada tiga karaketeristik yang menyatakan suatu teknologi menerapkan konsep Aumented Reality yaitu :

a. Mampu mengkombinasikan dunia nyata dan dunia maya,

b. Mampu memberikan informasi secara interaktif dan realtime,

c. Mampu menampilkan dalam bentuk 3D (tiga dimensi).

Vuforia adalah Augmented Reality Software Development Kit (SDK) untuk perangkat mobile yang memungkinkan pembuatan aplikasi AR. SDK. Vuforia juga tersedia untuk digabungkan dengan Unity yaitu bernama Vuforia AR Extension for Unity. Vuforia merupakan SDK yang disediakan oleh Qualcomm untuk membantu para developer membuat 
aplikasi-aplikasi Augmented Reality (AR) di mobile phones (iOS, Android). SDK. AR Vuforia memberikan cara berinteraksi yang memanfaatkan kamera mobile phone untuk digunakan sebagai perangkat masukan, sebagai mata elektronik yang mengenali penanda tertentu, sehingga di layar bisa ditampilkan perpaduan antara dunia nyata dan dunia yang digambar oleh aplikasi. Dengan kata lain, Vuforia adalah SDK untuk computer vision based AR. Jenis aplikasi AR yang lain adalah GPS-based AR.

\subsection{Arsitektur Augmented Reality}

Arsitektur teknologi Augmented Reality menurut Indrawaty (2014) seperti yang terlihat pada gambar II.2 berikut ini:

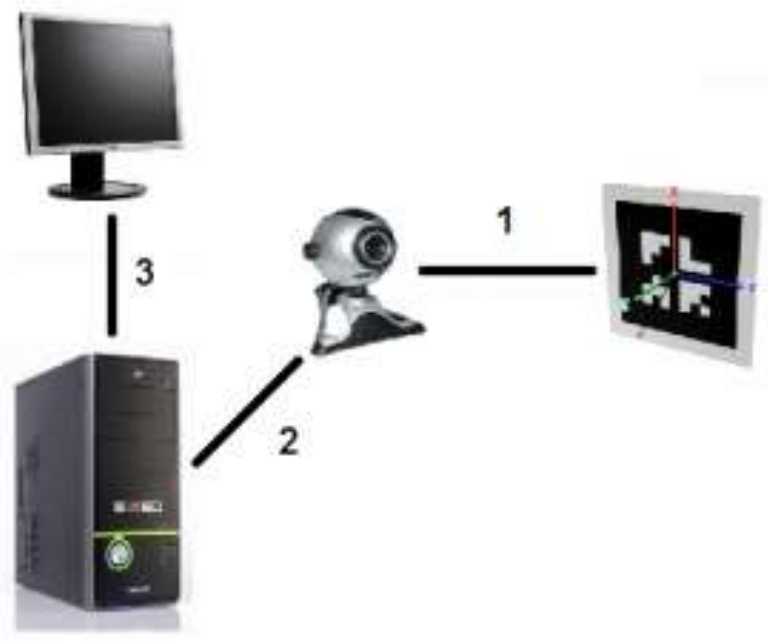

Gambar 1. Arsitektur Augmented Reality

a. Input

Input dapat berupa apa saja, contoh marker, gambar 2D, gambar 3D, sensor wifi, sensor gerakan, GPS, dan sensor-sensor yang lain.

b. Kamera

Kamera disini sebagai perantara untuk input yang berupa gambar, marker, gambar 2D maupun 3D.

c. Prosessor

Prosessor dibutuhkan untuk memproses input yang masuk dan kemudian memberikannya ke tahapan output.

d. Output

Dapat berupa Head Mounted Display (HMD), monitor, seperti monitor TV, LCD, monitor ponsel. 


\section{HASIL DAN PEMBAHASAN}

Berikut ini dijelaskan tentang tampilan hasil dari Perancangan Implementasi Augmented Reality Pada Hardware Komputer Berbasis Android dapat dilihat sebagai berikut :

Secara garis besar, bisnis proses sistem yang akan dirancang digambarkan dengan use case diagram yang terdapat pada Gambar 2 :

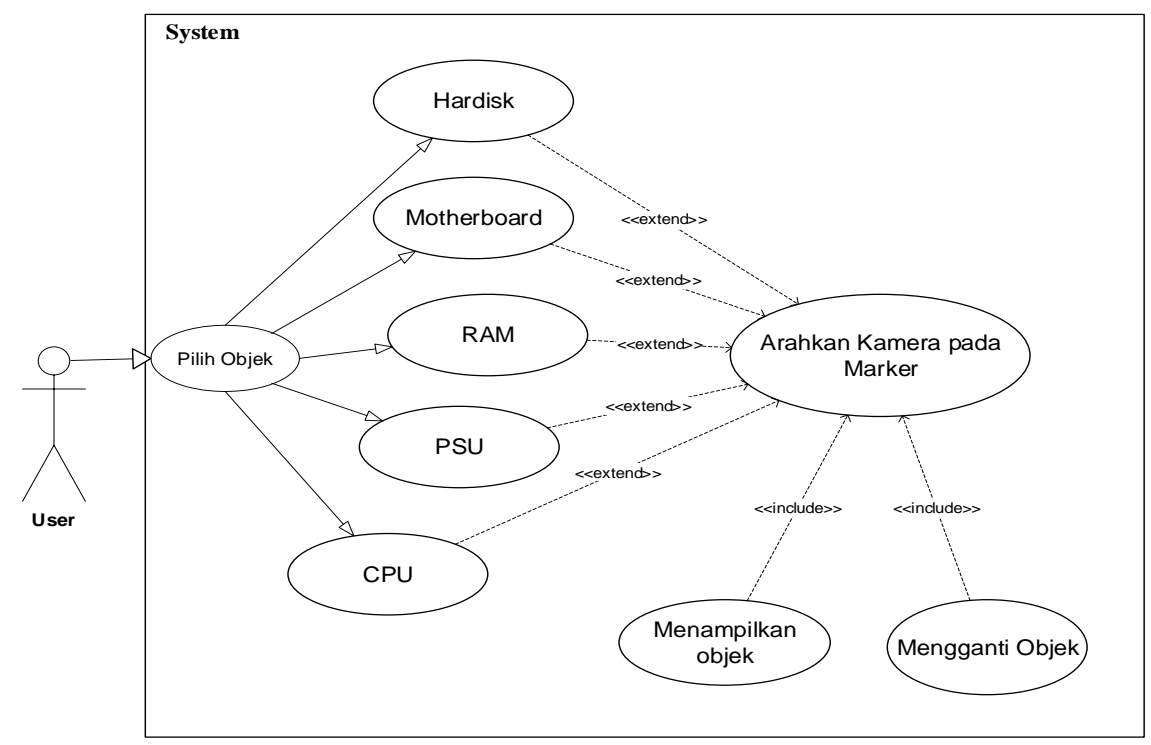

Gambar 2. Diagram Use-Case Menampilkan Objek AR

\subsection{Tampilan Hasil}

Berikut ini adalah tampilan hasil dari program Perancangan Implementasi Augmented Reality Pada Hardware Komputer Berbasis Android:

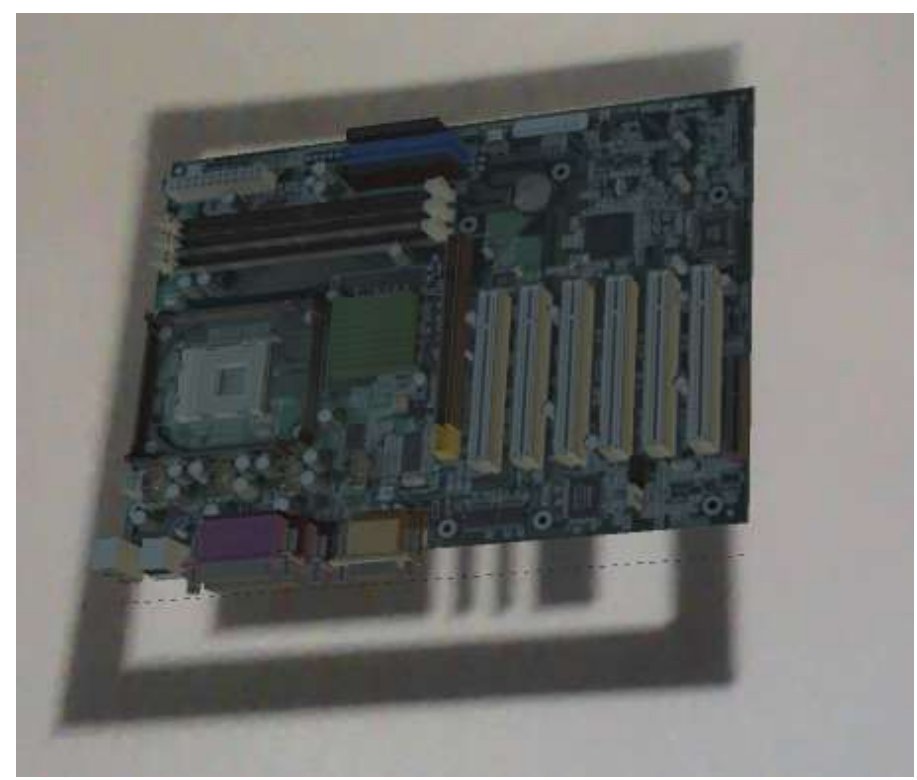

Gambar 3. Augmented Reality Motherboard 


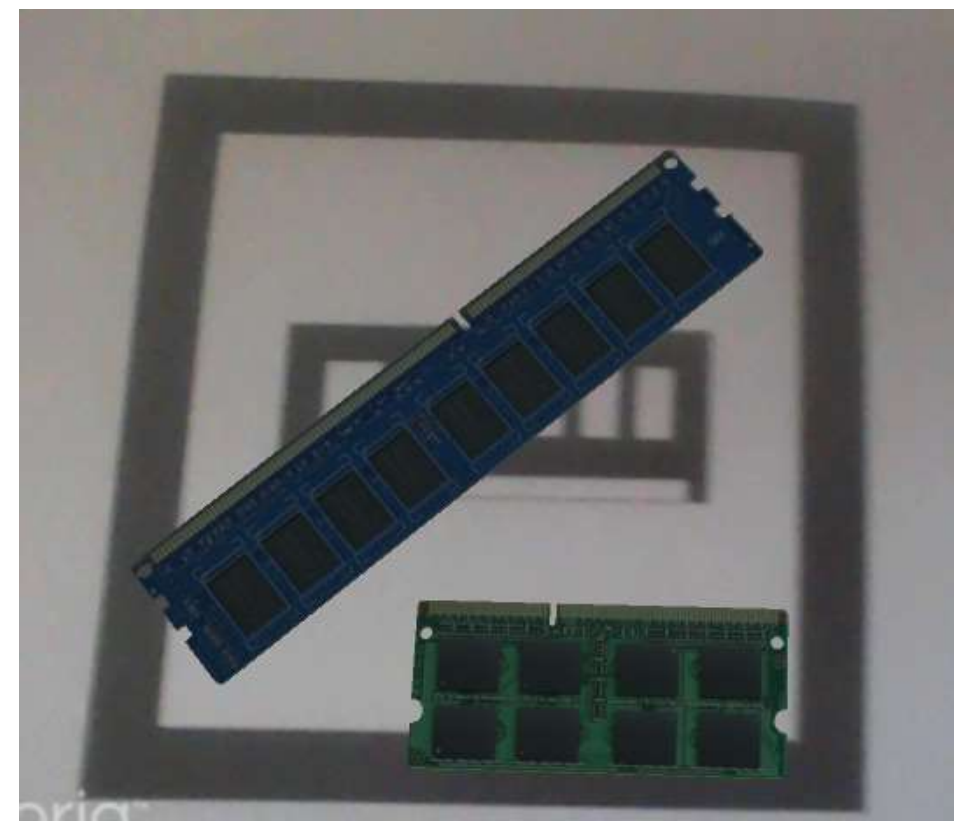

Gambar 4. Augmented Reality RAM

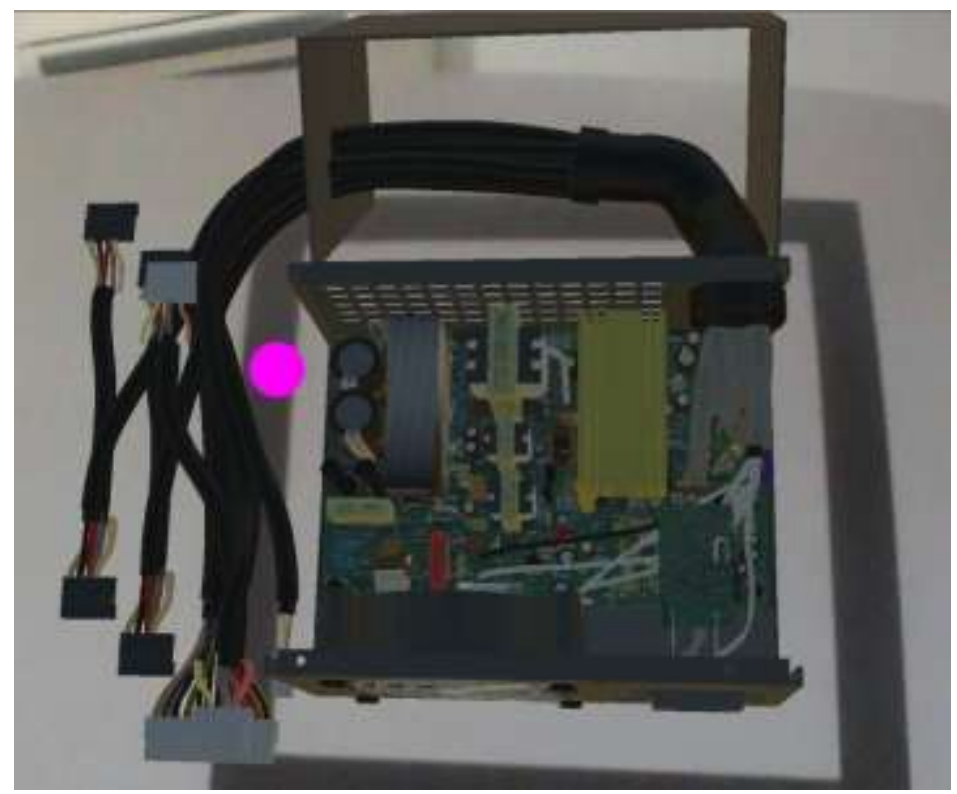

Gambar 5. Augmented Reality Power Supply 


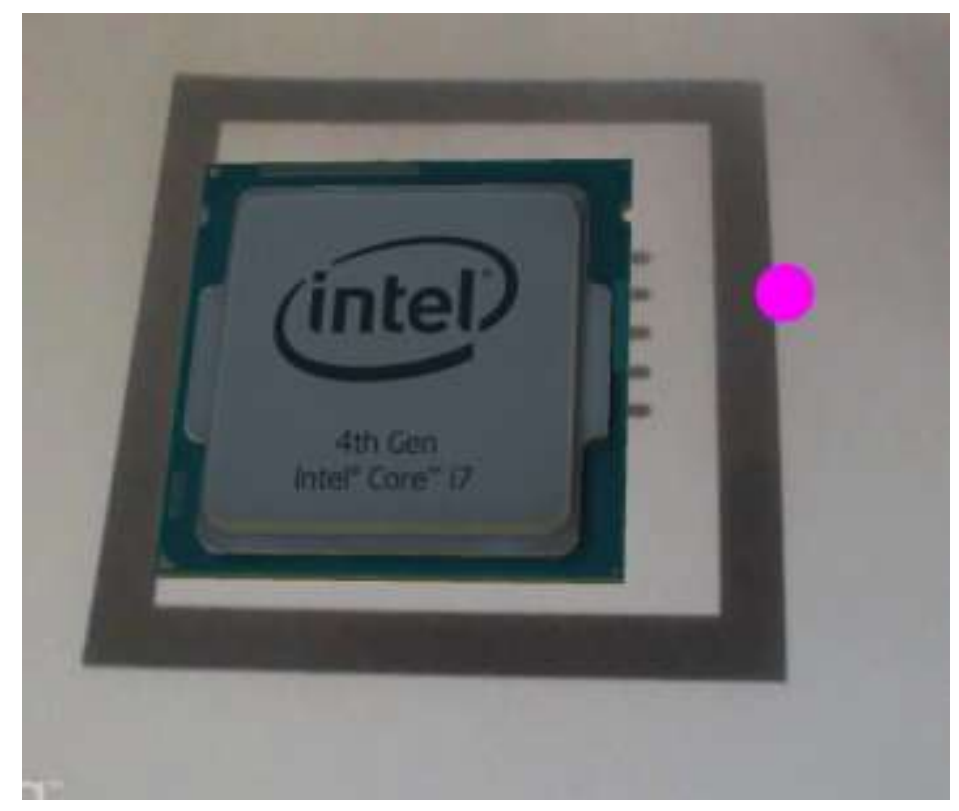

Gambar 6. Augmented Reality Processor

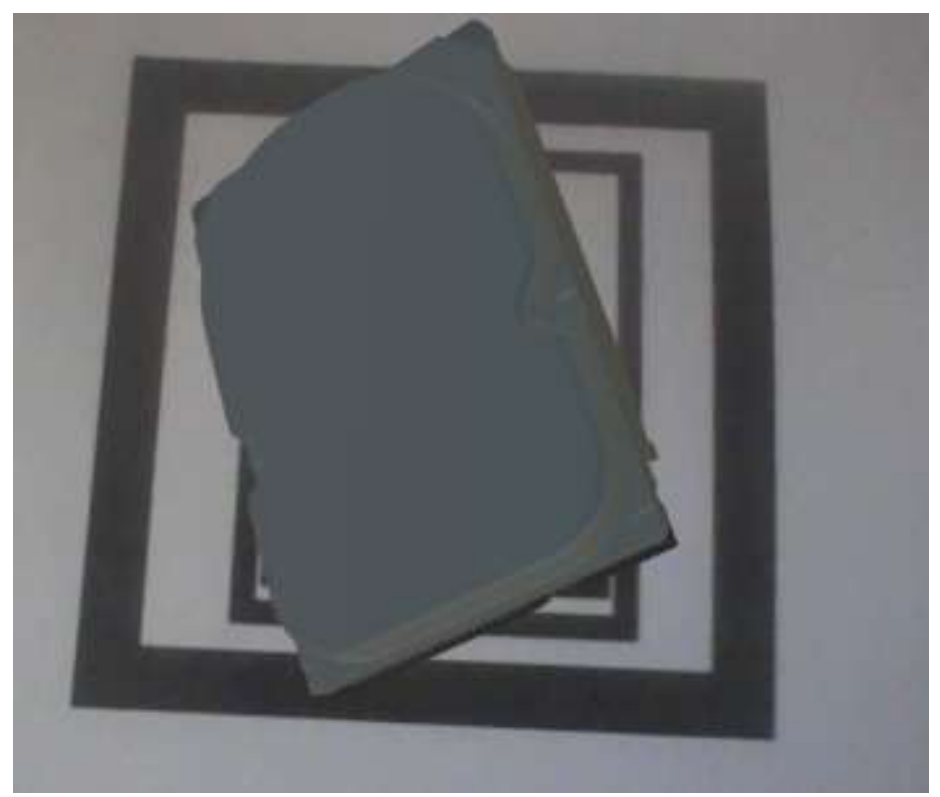

Gambar 7. Augmented Reality Harddisk

\subsection{Uji Coba}

Uji coba hasil merupakan tahap dimana kita dapat mengetahui dan menguji semua element element perangkat lunak yang dibuat apakah berjalan sesuai dengan yang diharapkan.

Tabel 1. Hasil Pengujian Aplikasi Augmented Reality

\begin{tabular}{|l|l|l|c|}
\hline No & Pengujian & Hasil yang diharapkan & Hasil Pengujian \\
\hline 1 & Harddisk & Halaman AR menampilkan objek & Baik \\
\hline
\end{tabular}




\begin{tabular}{|l|l|l|c|}
\hline & & Harddisk & \\
\hline 2 & Motherboard & $\begin{array}{l}\text { Halaman AR menampilkan objek } \\
\text { Motherbiard }\end{array}$ & Baik \\
\hline 3 & RAM & $\begin{array}{l}\text { Halaman AR menampilkan objek } \\
\text { RAM }\end{array}$ & Baik \\
\hline 4 & Processor & $\begin{array}{l}\text { Halaman AR menampilkan objek } \\
\text { Processor }\end{array}$ & Baik \\
\hline 5 & Power Supply & $\begin{array}{l}\text { Halaman AR menampilkan objek } \\
\text { Power Supply }\end{array}$ & Baik \\
\hline
\end{tabular}

\subsection{Skenario Pengujian}

Pengujian terhadap sistem bertujuan untuk memastikan bahwa sistem berada pada kondisi siap pakai. Ada beberapa instrumen pengujian yang dilakukan untuk menguji program ini yaitu :

\section{Evaluasi Kepada User}

Evaluasi kepada user digunakan untuk mengetahui apakah aplikasi ini memberi hal yang positif kepada user untuk digunakan dalam hal belajar mengajar. Evaluasi menggunakan metode kuisioner yang diberikan setelah menggunakan aplikasi. Jumlah user sebanyak 10 orang. Kuisioner pada tabel 2, berisi tentang pertanyaan yang berkaitan dengan aplikasi.

Tabel 2. Hasil Kuisioner

\begin{tabular}{|c|c|c|c|c|c|}
\hline \multirow{2}{*}{ No } & \multirow{2}{*}{ Pertanyaan } & \multicolumn{4}{|c|}{ Jawaban } \\
\hline & & $\mathbf{A}$ & B & $\mathbf{C}$ & D \\
\hline 1 & $\begin{array}{ll}\text { Desain } & \text { Tampilan } \\
\text { Aplikasi } & \text { Pengenalan } \\
\text { Hardware } & \text { Komputer }\end{array}$ & 8 & 2 & 0 & 0 \\
\hline 2 & Visualisasi Objek 3D & 8 & 2 & 0 & 0 \\
\hline 3 & $\begin{array}{l}\text { Aplikasi sebagai media } \\
\text { belajar mengajar }\end{array}$ & 3 & 7 & 0 & 0 \\
\hline 4 & $\begin{array}{ll}\text { Aplikasi } \quad \text { yang } & \text { User } \\
\text { Friendly } & \end{array}$ & 8 & 2 & 0 & 0 \\
\hline 5 & $\begin{array}{l}\text { Objek 3D menyerupai } \\
\text { benda nyata }\end{array}$ & 6 & 4 & 0 & 0 \\
\hline
\end{tabular}




\begin{tabular}{|l|l|c|c|c|c|} 
& & & \\
\hline 6 & $\begin{array}{l}\text { Keinginan } \\
\text { Menggunakan Aplikasi }\end{array}$ & 7 & 3 & 0 & 0 \\
\hline Total & $\mathbf{5 6}$ & $\mathbf{2 3}$ & $\mathbf{1}$ & $\mathbf{0}$ \\
\hline
\end{tabular}

\section{KESIMPULAN}

Berdasarkan hasil studi literatur, analisis, perancangan, implementasi, dan pengujian sistem ini, maka kesimpulan yang didapat adalah sebagai berikut:

1. Membangun aplikasi Augmented Reality dapat bermanfaat bagi pengguna khususnya siswa/i maupun mahasiswa/i dalam pemahaman hardware komputer.

2. Objek 3D yang dibuat berdasarkan gambar asli.

3. Teknologi Augmented Reality sangat membantu siswa/i maupun mahasiswa/i dalam proses belajar mengajar dapat menjadikan proses belajar mengajar tidak statis dan memberikan daya tarik kepada siswa/i maupun mahasiswa/i.

\section{SARAN}

Sebagai aplikasi yang tidak dikerjakan dengan tim, penulis menyadari bahwa aplikasi ini memiliki banyak kekurangan, saran untuk pengembangan aplikasi pada waktu mendatang yaitu sebagai berikut :

1. Diharapkan pada penelitian selanjutnya dapat menyediakan beberapa fitur yang lebih interaktif.

2. Diharapkan pada penelitian selanjutnya memiliki banyak objek 3D

\section{UCAPAN TERIMA KASIH}

Penulis mengucapkan terimah kasih kepada Universitas Potensi Utama yang telah memberikan kesempatan pada penulis agar menyelesaikan karya ilmiah ini untuk melengkapi persyaratan penyelesaian tugas akhir atau skripsi penulis. Dan berterima kasih banyak kepada Bapak Edy Victor Haryanto M.Kom, yang telah memberi arahan dan bimbingan dalam penulisan karya ilmiah. 


\section{DAFTAR PUSTAKA}

[1] Tifando Zulfikar Kasih, 2014, Jurnal : Aplikasi Augmented Reality Sebagai Media Pembelajaran Manasik Haji Berbasis Android Device, Fakultas Teknik Jurusan Teknik Elektro, Universitas Muhammadiyah Surakarta.

[2] Risyan, Afdhol, 2016. Jurnal :Analisis Penggunaan Metode Marker Tracking Pada Augmented Reality Alat Musik Tradisional Jawa Tengah”, Teknik Informatika, Politeknik Negeri Batam.

[3] Meyti Eka Apriyani, dkk, 2016. Jurnal : Analisis Penggunaan Marker Tracking Pada Augmented Reality Huruf Hijaiyah”, Teknik Informatika, Politeknik Negeri Batam.

[4] Fahreza Fauzi Putra, dkk, 2012. Jurnal : Aplikasi Pembelajaran Metamorfosis Berbasis Android Augmented Reality”, Teknik Informatika Vol 1, Politeknik Negeri Batam.

[5] Ida Bagus Made Mahendra, 2016. Jurnal : Implementasi Augmented Reality (AR) Mengunakan Unity 3D Dan Vuporia SDK”, Teknik Informatika Vol.9, No.1, Universitas Udayana. 